\title{
Feasibility of a New Method for Identification and Discrimination of Gunshot Residues by Total Reflection X-Ray Fluorescence and Principal Component Analysis
}

\author{
Luisa P. Ferreira, ${ }^{a}$ Clésia C. Nascentes, ${ }^{\circledR} *, a$ Frederico $N$. Valladão ${ }^{b}$ and \\ Rogério A. Lordeiro ${ }^{b}$ \\ ${ }^{a}$ Departamento de Química, Universidade Federal de Minas Gerais, \\ Avenida Presidente Antônio Carlos, 6627, 31270-901 Belo Horizonte-MG, Brazil \\ ${ }^{b}$ Seção Técnica de Química e Física Legal do Instituto de Criminalística da Polícia Civil de Minas Gerais, \\ Rua Juiz de Fora, 400, 30180-060 Belo Horizonte-MG, Brazil
}

\begin{abstract}
This study aims at identifying and discriminating gunshot residue (GSR) from conventional ammunition of six different calibers by total reflection X-ray fluorescence (TXRF) and pattern recognition by principal component analysis (PCA). GSR samples were collected from hands of volunteer shooters with swabs moistened with deionized water and were extracted with $5 \% \mathrm{v} \mathrm{v}^{-1}$ nitric acid. Aliquots were deposited on quartz disks for further determination by TXRF of the elements $\mathrm{Al}, \mathrm{S}, \mathrm{Ca}, \mathrm{K}, \mathrm{Mn}, \mathrm{Fe}, \mathrm{Ni}, \mathrm{Cu}, \mathrm{Zn}, \mathrm{Br}, \mathrm{Sr}, \mathrm{Sb}, \mathrm{Ba}$ and $\mathrm{Pb}$, whose concentrations were imported into the MATLAB ${ }^{\circledR}$ software for PCA execution. The method proved to be adequate for identification of one- and three-shot residue inorganic components from $.40,9 \mathrm{~mm}, .380, .38$ and .308 calibers, and of three-shot residues from .32 caliber, as well as for sample discrimination as a function of the conventional ammunition calibers studied.
\end{abstract}

Keywords: inorganic gunshot residue, ammunition discrimination, total reflection X-ray fluorescence, principal component analysis

\section{Introduction}

The detection and identification of gunshot residues (GSR) from firearm discharges provide valuable investigative information. ${ }^{1}$

When a projectile is expelled at the moment a cartridge is discharged by a firearm, residues are also emitted, which are composed of organic and inorganic vapors, gases and particles. ${ }^{2}$ These residues from pistols and long weapons (rifles and shotguns) escape mainly from the muzzle, but also from any slit in the gun, as well as from the gap between drum and barrel rear end and from the ejection port (where empty cartridge cases exit after a shot). These residues are deposited near where the shot occurred, on the shooter's hands, face, hair and clothing, and also on the target, as long as the distance between muzzle and target is sufficiently short-90 to $120 \mathrm{~cm}$, approximately. ${ }^{3,4}$ In addition, GSR that is deposited on the projectile is transferred by it to the perimeter of entrance hole in the target, which is independent of shooting distance. ${ }^{4}$ Analysis

*e-mail: clesia@qui.ufmg.br of GSR collected on the target allows distinction between entry and exit holes, estimation of shooting distance, determination of cartridge nature and inference about the projectile's trajectory. In addition, GSR analysis collected on the shooter can relate a suspect and the event. Knowledge of these various parameters assists in the interpretation of the event sequence of a crime. ${ }^{5}$

The availability of GSR is influenced by factors that cannot be controlled, such as type of firearm and mechanical condition, maintenance and preservation of the firearm, ammunition used (cartridge caliber and length, propellant energy, jacketed or unjacketed projectile), manner in which the shooter holds the gun to fire, number of shots, environmental circumstances (air currents, open or closed location), and nature of deposition surface (natural $\mathrm{pH}$, oils and moisture of skin, for example). . $^{3,4,6,7}$

Inorganic constituents present in GSR mostly come from the primer mixture, ${ }^{8}$ whose main components are lead styphnate, used as initiator, barium nitrate, used as oxidant, and antimony sulfide, used as fuel. At the present time, scanning electron microscopy combined with energy dispersive X-ray spectroscopy (SEM-EDX) is the most used 
technique for detection and chemical characterization of inorganic gunshot residue (IGSR) particles. ${ }^{9}$ According to the latest publication of the American Society for Testing and Materials, ${ }^{10}$ the criteria for classifying examined particles like GSR by SEM-EDX are based on morphology and elemental composition. Non-crystalline particles often spheroidal, with diameters ranging commonly from 0.5 to $5.0 \mu \mathrm{m}$, are considered "characteristic of" or "consistent with GSR", ${ }^{10}$ since such morphology expresses the kinetics of the rapid cooling process of molten material. ${ }^{11}$ In turn, elemental composition through the simultaneous determination of lead $(\mathrm{Pb})$, barium $(\mathrm{Ba})$ and antimony $(\mathrm{Sb})$ allows classifying particles as "characteristic of GSR". Likewise, particles can be classified as "consistent with" or "commonly associated with GSR" according to which combination of elements in Table 1 is detected. As shown in this table, other chemical elements are also found in GSR.

Although SEM-EDX occupies a prominent position in IGSR analysis for identifying morphological and elemental characteristics of each particle, it has the drawback of high instrumentation costs and long procedures that require specialized analysts. ${ }^{3,4}$ Recently, Romolo et al. ${ }^{12}$ demonstrated the use ion beam analysis (IBA) to GSR particles characterization. The comparison between spectra from the same particle obtained by SEM-EDX and IBA-PIXE (particle induced X-ray emission) showed that the latter is much more sensitive at mid-high energies. However, this instrumentation is also expensive and this technique not yet widespread. In this context, other techniques have been employed, such as graphite furnace atomic absorption spectroscopy (GF AAS), ${ }^{13}$ inductively coupled plasma mass spectrometry (ICP-MS), ${ }^{14,15}$ laser induced breakdown spectroscopy (LIBS) ${ }^{16}$ and inductively coupled plasma atomic emission spectrometry (ICP OES) ${ }^{17}$ These are mainly used in methods where prior to subjecting a sample to an analytical technique for the determination of total element concentrations, sample dissolution or extraction is performed, so that shape, size, and individual particle identification are impaired. ${ }^{10}$ In this case, the evaluation of the presence of metals from other sources, such occupational, is crucial for prevention of false positives, since this technique does not consider the individual particle morphology. ${ }^{13}$

In view of the above, it is important to develop methods that assess elemental profile of suspect samples, rather than just one or other characteristic combination of elements. Elemental profile analysis also enables discrimination among ammunition with respect to different calibers and manufacturers.

A multielemental technique, not yet reported in the GSR analysis, but with potential to obtain the elemental profile is total reflection X-ray fluorescence (TXRF). This technique is a powerful analytical multielemental tool due to its extensive detectable elemental range and simplicity of quantification. ${ }^{18}$ The total reflection of primary X-ray photons on the quartz carrier, containing a thin film of the sample, results in higher excitation efficiency, thereby resulting in lower detection limits. ${ }^{19}$ Moreover, the detector is installed perpendicular to the sample holder with a distance of less than $2 \mathrm{~mm}$ from the thin film, which widens the reception angle and allows registering the fluorescence with high efficiency. ${ }^{20,21}$

As a result of the TXRF's geometric conditions of excitation and detection, the technique has attractive features such as trace multielemental analysis (on the order of parts per billion-ppb, $\mu \mathrm{g} \mathrm{L}^{-1}$ or $\mu \mathrm{g} \mathrm{kg}^{-1}$ ). It also requires small sample amounts (about $10 \mu \mathrm{L}$ or $10 \mu \mathrm{g}$ ), admits simple internal standard calibration free of matrix effect correction, and is more sensitive. ${ }^{20,22}$

The profusion of information such as that obtained by multielemental techniques, which provide analytical signal intensities as a function of the energy of numerous electronic transitions in each spectrum corresponding to multiple samples, requires the application of multivariate analysis tools. ${ }^{23}$ Also, pattern recognition seeks to group samples that carry similarities and thus to reveal trends in the dataset. ${ }^{24}$ Principal component analysis (PCA), a pattern recognition method, projects samples (objects) into a lower-dimensional subspace, reducing the dimensionality

Table 1. Classification of particles detected by SEM-EDX according to the elemental composition ${ }^{10}$

\begin{tabular}{|c|c|c|}
\hline Characteristic of GSR & Consistent with GSR & Commonly associated with GSR \\
\hline (a) Lead, barium, antimony & (a) lead, barium, calcium, silicon & (a) lead \\
\hline \multirow[t]{5}{*}{ (b) Lead, barium, calcium, silicon, tin } & (b) barium, calcium, silicon & (b) antimony \\
\hline & (c) antimony, barium & (c) barium (sulfur can be present) \\
\hline & (d) lead, antimony & \\
\hline & (e) barium, aluminum & \\
\hline & (f) lead, barium & \\
\hline
\end{tabular}

GSR: gunshot residues. 
of the original data space, thus facilitating perception of the relevant information by visual inspection. ${ }^{25}$

In light of the foregoing, this work proposed an innovative method to characterize and distinguish gunshot residue from conventional ammunition of six different calibers by TXRF and pattern recognition by PCA.

\section{Experimental}

\section{Reagents and materials}

A $100 \mathrm{mg} \mathrm{L}^{-1}$ internal standard (Ga, Sigma-Aldrich ${ }^{\circledR}$ Fluka Analytical, Buchs, Switzerland) solution was prepared from a $1000 \mathrm{mg} \mathrm{L}^{-1}$ stock solution with deionized water, with resistivity of $18.2 \mathrm{M} \Omega \mathrm{cm}$ (Milli-Q-Millipore ${ }^{\circledR}$ DirectQ3, Billerica, USA). A $5 \% \mathrm{v} \mathrm{v}^{-1}$ solution of nitric acid $\left(\mathrm{HNO}_{3}\right)$ was prepared from the $65 \% \mathrm{~m} \mathrm{v}^{-1}$ concentrated solution (Merck, Darmstadt, Germany), without further purification, for analyte extraction.

Quartz glass disks with $30 \mathrm{~mm}$ diameter and thickness of $3.0 \pm 0.1 \mathrm{~mm}$ were applied as TXRF sample carriers. Acetone (Vetec, Rio de Janeiro, Brazil) and Extran MA02 detergent (Sigma-Aldrich GmbH, Seelze, Germany) were also used for cleaning the quartz sample carriers. The carriers were previously siliconized with $10 \mu \mathrm{L}$ of a silicon solution in isopropanol (ServaTM, Heidelberg, Germany) to make the surface of the quartz reflector hydrophobic and prevent the spread of the sample drop before analysis.

A multi-element solution containing $\mathrm{Al}, \mathrm{As}, \mathrm{Ba}, \mathrm{Cd}$, $\mathrm{Co}, \mathrm{Cr}, \mathrm{Cu}, \mathrm{Mn}, \mathrm{Mo}, \mathrm{Ni}, \mathrm{Pb}, \mathrm{Se}, \mathrm{Sr}, \mathrm{Zn}\left(5 \mathrm{mg} \mathrm{L}^{-1}\right)$ and $\mathrm{K}$ (50.0 $\left.\mathrm{mg} \mathrm{L}^{-1}\right)$ and monoelement solutions containing $\mathrm{Sb}$ and Ca (1000 mg L L $\mathrm{m}^{-1}$ (Specsol, São Paulo, Brazil) were used to prepare spiked samples to check the precision and accuracy of the method.

\section{Sample collection}

In order to reproduce the characteristics of real cases, GSR samples were collected in triplicate from the hands of volunteer shooters with swabs (J.Prolab ${ }^{\circledR}$, São Paulo, Brazil) moistened with ultrapure water ${ }^{23}$ on the thumb and forefinger palm and thumb and forefinger back regions, immediately after one and three shots. Control samples were also collected from water, gun, shooter's hand before firing and body (back of the neck), totaling 36 samples for each type of ammunition evaluated in this study. The body sample collection aimed to control possible environmental and occupational contamination. Prior to collection, guns were subjected to a cleaning procedure with tap water followed by absolute ethyl alcohol (reagent grade, Ensure, Merck, Darmstadt, Germany), and volunteer shooters were instructed to wash their hands with soap in running water before each experiment replicate to avoid contamination by previous discharges. Volunteers performed the shots holding the weapons only with the right hand. Six conventional ammunition calibers (Table 2) were evaluated.

\section{Sample preparation}

The swabs were stored in $5.0 \mathrm{~mL}$ capped polyethylene tubes in which the liquid extraction of inorganic components was promoted by addition of $490 \mu \mathrm{L}$ of $5 \% \mathrm{v} \mathrm{v}^{-1}$ nitric acid and $10 \mu \mathrm{L}$ of $100 \mathrm{mg} \mathrm{L}^{-1}$ gallium as internal standard (IS final concentration of $2 \mathrm{mg} \mathrm{L}^{-1}$ ) and subsequent sonication (ultrasonic bath, UNIQUE, model Ultracleaner $1400 \mathrm{~A}$, Indaiatuba, Brazil) for $5 \mathrm{~min}$. This procedure was adapted from the protocol of GSR analysis by GFAAS utilized by Civil Police of Minas Gerais. A volume of $10 \mu \mathrm{L}$ of the resulting solution was deposited on previously decontaminated quartz disks (sample support) for further TXRF analysis, and the disks were then dried in an oven (TECNAL, model TE-394/I, São Paulo, Brazil) at $60{ }^{\circ} \mathrm{C}$ for $15 \mathrm{~min}$.

\section{Instrumentation and analysis conditions}

Determination of inorganic constituents was conducted with a total refection X-ray fluorescence spectrometer, model S2 PICOFOX ${ }^{\mathrm{TM}}$ (Bruker Nano GmbH, Berlin, Germany).

Table 2. List of ammunitions and respective firearms used to discharge them in this study

\begin{tabular}{|c|c|c|}
\hline Caliber & Manufacturer and bullet characteristics & Firearm \\
\hline $9 \mathrm{~mm}$ Luger & $\mathrm{CBC}^{\circledR}$ full metal jacket (FMJ) & Taurus $^{\circledR} 9 \mathrm{~mm} 24 / 7 \mathrm{G} 2$ pistol \\
\hline $.38 \mathrm{SPL}$ & $\mathrm{CBC}^{\circledR}$ lead round nose (LRN) unjacketed & Taurus $^{\circledR} .38$ SPL RT 82 revolver \\
\hline .32 S\&W Long & $\mathrm{CBC}^{\circledR}$ semi jacketed hollow point (SJHP) & Smith \& Wesson ${ }^{\circledR}$ Long .32 revolver \\
\hline $.380+\mathrm{P}$ & $\mathrm{CBC}^{\circledR}$ jacketed hollow point $(\mathrm{JHP})+\mathrm{P}$ & IMBEL $^{\circledR} .380$ pistol \\
\hline $.40 \mathrm{~S} \& \mathrm{~W}$ & $\mathrm{CBC}^{\circledR}$ full metal jacket flat (FMJ Flat) & IMBEL $^{\circledR} .40$ pistol \\
\hline \multirow[t]{2}{*}{.308 WIN. } & Sellier \& Bellot & IWI $^{\circledR}$ Galil ACE .308 WIN. rifle \\
\hline & & IMBEL $^{\circledR}$ AGLC .308 rifle \\
\hline
\end{tabular}

CBC: Companhia Brasileira de Cartuchos; IMBEL: Indústria de Material Bélico do Brasil. 
The X-ray tube with a Mo (molybdenum) anode (17.5 keV) was operated at $50 \mathrm{kV}$ and $600 \mu \mathrm{A}$. The characteristic X-rays were detected by a $10 \mathrm{~mm}^{2}$ silicon-drift detector, under air atmosphere. The resolution (full width at half maximum, FWHM) was $<160 \mathrm{eV}$ for Mn K $\alpha 10 \mathrm{kcps}$, while the beryllium window was $100 \mu \mathrm{m}$ thick. The excitation time used was $250 \mathrm{~s}$. Spectra evaluation and element quantification were performed with the PICOFOX software. ${ }^{26}$ The Bayes deconvolution was performed with all spectra.

Some parameters of the spectrometer were evaluated and calibrated periodically to guarantee the quality of the results: gain correction, spectroscopic resolution, sensitivity and accuracy of the quantification. ${ }^{21}$

To check the precision and accuracy of the method an acid solution containing $\mathrm{Al}, \mathrm{Fe}, \mathrm{Mn}, \mathrm{Ni}, \mathrm{Cu}, \mathrm{Zn}, \mathrm{Sr}$, $\mathrm{Sb}, \mathrm{Ba}$ and $\mathrm{Pb}\left(500 \mu \mathrm{g} \mathrm{L}^{-1}\right)$ and $\mathrm{Ca}$ and $\mathrm{K}\left(5 \mathrm{mg} \mathrm{L}^{-1}\right)$ was analyzed $(n=7)$.

\section{Chemometric analysis}

Concentrations of the elements Al, S, Ca, K, Mn, Fe, $\mathrm{Ni}, \mathrm{Cu}, \mathrm{Zn}, \mathrm{Br}, \mathrm{Sr}, \mathrm{Ba}$ and $\mathrm{Pb}$ in $\mathrm{mg} \mathrm{L}^{-1}$ were imported into Matlab ${ }^{\circledR} 7.12$ software (R2011a version) from MathWorks. ${ }^{27}$ Pre-processing and PCA models were performed using PLS Toolbox ${ }^{\circledR}$ (6.7.1 version) from Eigenvector Technologies. ${ }^{28}$ Instrumental responses were not used for chemometric analysis because the concentration values already contemplate corrections, such as irregularity of sample dispersion on quartz disk, when internal standard calibration is used..$^{29}$

For all analyses, data were preprocessed by autoscaling, since concentration values of each element (variable) belong to different distributions, ${ }^{23}$ although they are in the same units, $\mathrm{mg} \mathrm{L}^{-1}$. When running autoscaling, after mean centering, data are divided by standard deviation of each column, in order to assign the same weight to all variables.

Values below the limit of detection were filled with zero. The number of principal components used in the PCA models was based on eigenvalue versus number of PC plots. Detection and exclusion of outliers were carried out by analyzing $Q$ residuals versus Hotelling $\mathrm{T}^{2}$ plot. Samples with high $\mathrm{Q}$ residuals (poorly modeled) and high Hotelling $\mathrm{T}^{2}$ (high influence on model) were excluded and the model was reconstructed. ${ }^{23}$

\section{Results and Discussion}

\section{TXRF analysis}

In the TXRF analysis, the formation of a thin layer from liquid or solid samples enables the elimination of matrix effects and the application of internal standardization. ${ }^{19}$ Unknown concentrations of elements to be determined can be calculated by comparing element net intensity and internal standard net intensity and concentration, in accordance with equation $1 .^{20,21}$

$\mathrm{C}_{\mathrm{i}}=\frac{\mathrm{I}_{\mathrm{i}}}{\mathrm{I}_{\mathrm{IS}}} \times \mathrm{s}_{\mathrm{i}} \times \mathrm{C}_{\mathrm{IS}}$

where i represents the element to be determined, IS the element used as internal standard, $\mathrm{C}$ is the concentration, $\mathrm{S}$ is the relative element sensitivity (dimensionless, in relation to the element used as internal standard) and I is the characteristic X-ray intensity, in counts per second (cps).

For the quantitative elemental determination by internal standardization, a known amount of a monoelement standard solution was added to the extracts. The choice of the internal standard is conditioned to its absence in the samples and also to the elemental composition of the latter. Another requirement is that the fluorescence lines of the internal standard do not interfere with the lines of analytes. In this way, $\mathrm{Ga}\left(\mathrm{K}_{\beta 1}=10.26 \mathrm{keV}\right)$ was chosen for GSR analysis where $\mathrm{Al}, \mathrm{S}, \mathrm{Ca}, \mathrm{K}, \mathrm{Mn}, \mathrm{Fe}, \mathrm{Ni}, \mathrm{Cu}, \mathrm{Zn}, \mathrm{Br}$, $\mathrm{Sr}, \mathrm{Sb}, \mathrm{Ba}$ and $\mathrm{Pb}$ were quantified. Although $\mathrm{Pb}, \mathrm{Ba}$ and $\mathrm{Sb}$ are the elements most related to inorganic GSR, these other elements were included to aid in the distinction of different types of ammunition.

The principal analytical characteristics of the method are presented in Table 3. Bromide and sulfur were not included in this evaluation because reference solutions were not available in the laboratory. Limits of detection ranged from $1.00 \mu \mathrm{g} \mathrm{L}{ }^{-1}(\mathrm{Sr})$ to $20.5 \mu \mathrm{g} \mathrm{L}^{-1}(\mathrm{~K})$. The relative standard deviation (RSD, \%) and recovery ranged from 3.41 to $6.51 \%$ and from 94.96 to $113.9 \%$, respectively, except to $\mathrm{Al}$ and $\mathrm{Sb}$. The aluminum concentration used in this evaluation $\left(500 \mu \mathrm{g} \mathrm{L}^{-1}\right)$ was lower than the limit of detection (LOD) obtained $\left(680 \mu \mathrm{g} \mathrm{L}^{-1}\right)$ and therefore the precision and accuracy obtained for this element were worse than for the other elements studied. However, in general, in the GSR samples Al concentrations were well above the detection limit.

Antimony cannot be quantified with good accuracy and precision because a spectral overlap occurs when the concentration of $\mathrm{Ca}$ is much higher than the concentration of Sb. Antimony L line $\left(\mathrm{L}_{\alpha 1}=3.6038\right)$ are overlapped by calcium $\mathrm{K}$ line $\left(\mathrm{K}_{\alpha 1 .}=3.6923\right)$ (Figure 1) and the Bayes deconvolution was not enough to obtain satisfactory results. Another study was carried out with different proportions of $\mathrm{Sb}$ and $\mathrm{Ca}$ (Sb:Ca from 2:1 to 1:10). In this study, when the calcium concentration increases the recovery of $\mathrm{Sb}$ decreases due to overlap, that is not adequately corrected 


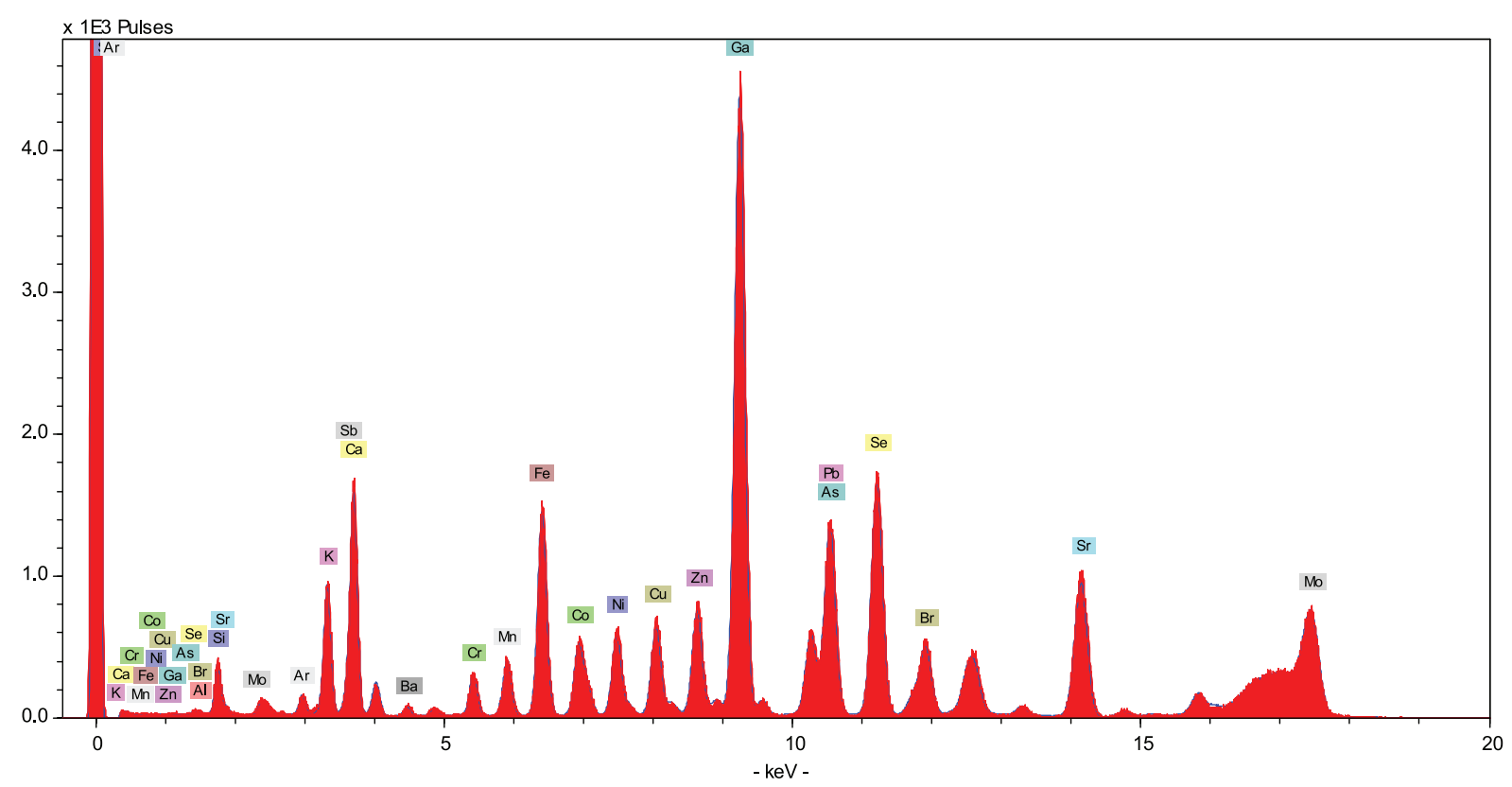

Figure 1. Fluorescence spectrum of the sample used in the accuracy and precision study.

by deconvolution (Supplementary Information (SI) section, Figure S1). Using Mo tube is not possible to access the antimony $\mathrm{K}$ lines. An alternative to quantify $\mathrm{Sb}$ in the presence of high concentrations of $\mathrm{Ca}$ would be to use a tungsten tube. Lead and As undergo similar interference, however, other non-overlapping peaks are selected in order to perform quantification. ${ }^{30}$

Table 3. Precision, accuracy and limits of detection obtained by TXRF $(\mathrm{n}=7)$

\begin{tabular}{lccc}
\hline Element & Recovery / $~$ & RSD / $\%$ & LOD / $\left(\mu \mathrm{g} \mathrm{L}^{-1}\right)$ \\
\hline $\mathrm{Al}$ & 169.3 & 26.2 & 680 \\
$\mathrm{~K}$ & 95.56 & 4.03 & 20.5 \\
$\mathrm{Ca}$ & 100.3 & 6.51 & 13.0 \\
$\mathrm{Mn}$ & 94.96 & 4.00 & 3.25 \\
$\mathrm{Fe}$ & 110.8 & 4.25 & 2.75 \\
$\mathrm{Ni}$ & 97.05 & 4.27 & 2.25 \\
$\mathrm{Cu}$ & 103.3 & 3.95 & 2.25 \\
$\mathrm{Zn}$ & 100.8 & 4.48 & 2.25 \\
$\mathrm{Sr}$ & 96.43 & 3.41 & 1.00 \\
$\mathrm{Sb}$ & 39.16 & 17.1 & 31.0 \\
$\mathrm{Ba}$ & 113.9 & 4.09 & 12.5 \\
$\mathrm{~Pb}$ & 95.38 & 3.71 & 2.00 \\
\hline
\end{tabular}

RSD: relative standard deviation; LOD: limit of detection.

\section{Identification and differentiation of GSR using chemometric} analysis

At first, to evaluate the method's efficiency in differentiating blank samples from real samples, separate PCA models were constructed for each firearm with the groups of back, palm and controls of deionized water, gun, body and hand (prior to shooting). Concentration values were arranged in the $\mathbf{X}$ matrix so that elements (variables) stayed in columns and samples (objects) stayed in rows. Back, palm and gun control samples were expected to be grouped in score plots and separated from water, body and hand control samples, which would be natural since the former are supposed to be positive and the latter, negative.

Model biplots were constructed for each type of ammunition, in which both scores and loadings were represented simultaneously. Figure 2 refers to .40 caliber ammunition, in which one can verify, albeit slightly, substantial separation of back (represented by inverted red triangles), palm (green asterisks) and gun samples (blue crosses) from water (blue squares), body (hollow lozenges) and hand samples (black triangles contoured in red) in $\mathrm{PC} 2$, which brings $\mathrm{Pb}, \mathrm{Cu}, \mathrm{Ba}, \mathrm{Ni}$ and $\mathrm{K}$ as elements (variables) with highest factor loadings. Copper and nickel are constituents of cartridge cases and bullet jackets, and potassium is a constituent of propellants and primers. ${ }^{4,8}$ The first four principal components explained $81.31 \%$ of the data variance. The fact that palm samples were close to blank samples (water, body and hand samples) suggests the pistol grip cleaning was sufficient to mitigate transfer of residues from previous use of the firearm to the palm by mere contact, and suggests GSR deposition occurred in a smaller amount than on the back, bringing spectral profile of these samples closer to profile of water, body and hand controls.

The low percentages of variance explained results from the highly heterogeneous nature of GSR samples, which 
is consistent with what was discussed in the Introduction section. Besides the factors that affect the probability of residue detection, which are not controlled, other factors are added, such as efficiency of sample collection, analytes extraction from swabs and instrumental limitations. ${ }^{6,31}$ The results of $9 \mathrm{~mm}, .380$ and .308 caliber conventional ammunition were consistent with those of .40 caliber, so their biplots are omitted.

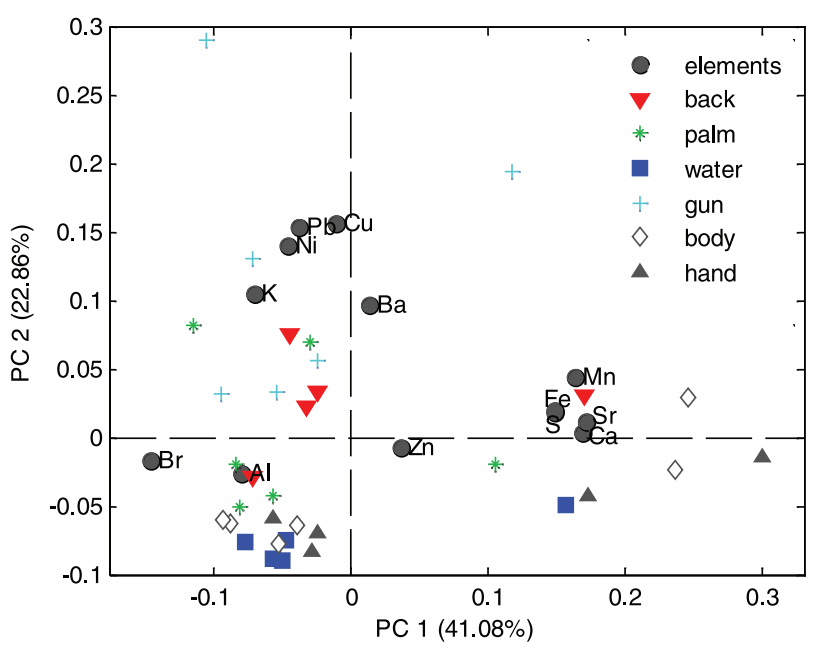

Figure 2. PC1 $\times$ PC2 biplot for .40 caliber ammunition.

Figure 3 refers to the model constructed for .38 caliber ammunition with four PCs, which explained $81.78 \%$ of data variance, and Figure 4 refers to the model constructed for .32 caliber with five PCs, which explained $90.53 \%$ of data variance. These figures reveal that the sample distribution in the new coordinate systems exhibited a difference in relation to collected from ammunition discharged by .40, $9 \mathrm{~mm}$ and .380 caliber pistols. The PCs that best separated back samples for .38 ammunition (Figure 3 ) were PC2 and $\mathrm{PC} 4$, and variables related to this separation were $\mathrm{Al}, \mathrm{Ba}$, $\mathrm{Cu}, \mathrm{Fe}, \mathrm{Ni}, \mathrm{Pb}$ and $\mathrm{Zn}$. In contrast, for .32 ammunition (Figure 4), the model separated only the three-shot replicates of back, palm and gun. The grouping of one-shot replicates of back with hand and body samples allows the interpretation that the method was not sensitive enough to discriminate one-shot GSR samples from samples presumed to be blank for the ammunition and firearm combination studied.

These changes in behavior of .32 and .38 datasets noted in comparison to $.40,9 \mathrm{~mm}$ and .380 data reveal the influence of weapon construction, which determines distinct formation of GSR plume by revolvers and pistols. While pistols release GSR through the ejection port, revolvers emit it through the gap between the drum and the barrel entrance. Both weapon types expel residues from the muzzle, although only a small portion reaches the shooter's

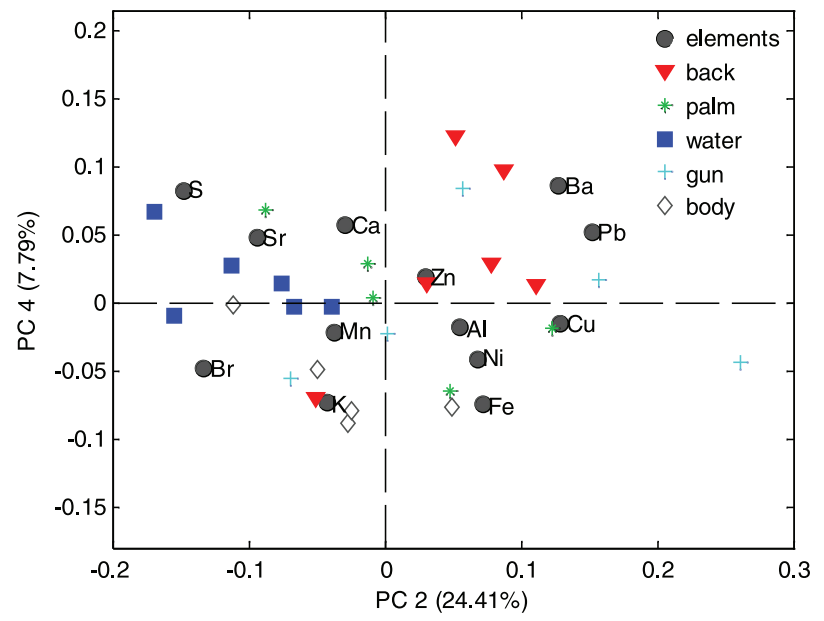

Figure 3. PC $2 \times \mathrm{PC} 4$ biplot for .38 caliber ammunition.

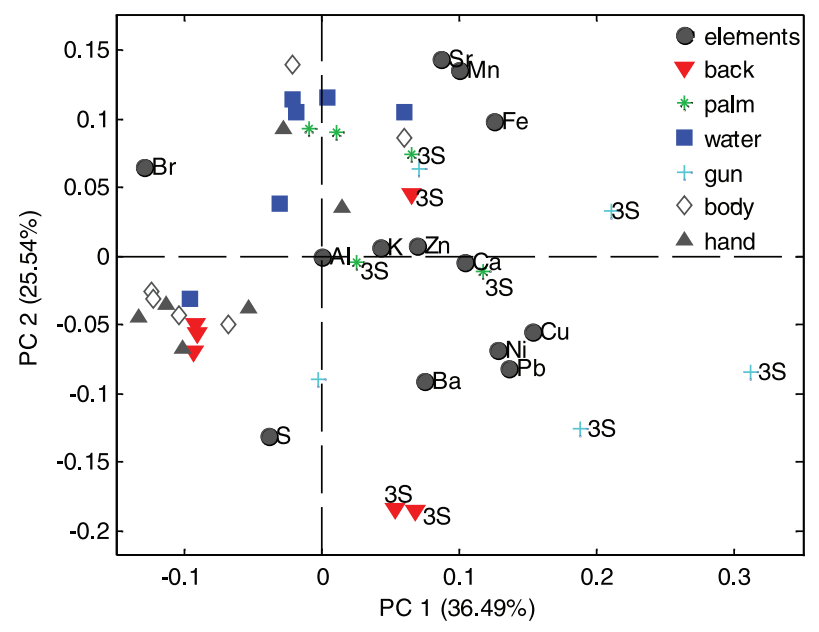

Figure 4. $\mathrm{PC} 1 \times \mathrm{PC} 2$ biplot for .32 caliber ammunition.

hands, depending on barrel length and gunpowder type, for example. ${ }^{32}$

The grouping of back replicates collected after one discharge of .32 ammunition to hand and body samples could be explained by the smaller caliber, which contains less gunpowder, and, consequently contributes less to the release of components external to it, coming from the projectile core $(\mathrm{Pb})$, the cartridge case and the projectile jacket $(\mathrm{Cu}, \mathrm{Zn}, \mathrm{Ni})$, and the barrel of the weapon $(\mathrm{Fe})$.

With the intention of not only identifying GSR, but also investigating the method's ability to discriminate residues as a function of firearm and ammunition associations-which in this work was restricted to caliber (since only one weapon with one ammunition type were combined, without varying manufacturer or model), a PCA model was constructed with the back samples of all calibers studied. One-shot replicates of .32 were not included because its model made no difference between these samples and the blank ones. 
The model with four PCs explained $83.45 \%$ of data variance, grouped the samples of $.40,9 \mathrm{~mm}, .380$ and .38 ammunition, and separated the samples of .32 and .308 ammunition in the $\mathrm{PC} 1 \times \mathrm{PC} 2 \times \mathrm{PC} 3$ biplot (Figure 5). The elements $\mathrm{K}, \mathrm{Ni}, \mathrm{Zn}$ and $\mathrm{Cu}$ had a larger contribution in .308 samples, while $\mathrm{S}, \mathrm{Ca}, \mathrm{Sr}$ and $\mathrm{Pb}$ contributed more in .32 samples.

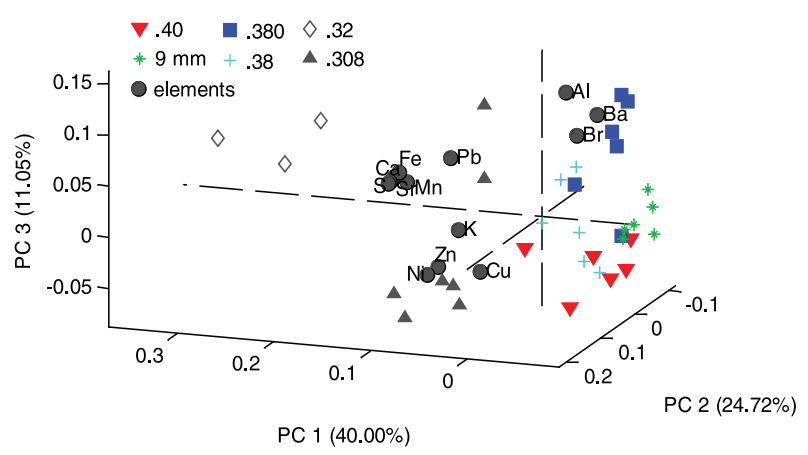

Figure 5. PC1 $\times$ PC2 $\times$ PC 3 biplot for $.40,9 \mathrm{~mm}, .380, .38, .32$ and .308 caliber ammunition.

Moreover, a model with only the handguns, without .308 caliber (rifle), was constructed (Figure 6). Principal component 1 separated .32 samples, in which $\mathrm{Ca}, \mathrm{S}, \mathrm{Sr}$ and $\mathrm{Pb}$ contributed most; $\mathrm{PC} 3$ separated .380 samples, in which Ba had the greatest contribution, from . 38 samples, in which $\mathrm{Ni}$ and K contributed most; and PC2 separated .308 and .38 samples from the other three calibers (.40,9 $\mathrm{mm}$ and .32$)$.

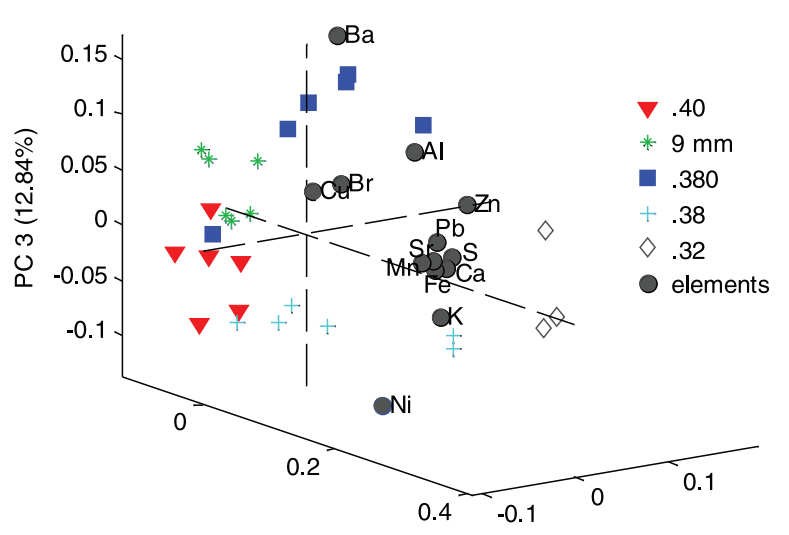

PC $1(45.51 \%)$

PC $2(15.36 \%)$

Figure 6. $\mathrm{PC} 1 \times \mathrm{PC} 2 \times \mathrm{PC} 3$ biplot for $.40,9 \mathrm{~mm}, .380, .38$ and .32 caliber ammunition.

\section{Conclusions}

This work reports for the first time the use of the TXRF technique for IGSR analysis. The technique requires small sample amounts, is highly sensitive and enables trace multielement analysis and internal standard calibration, making it a good alternative to other spectroscopic techniques. The method developed for gunshot residue detection from hands of shooters by TXRF proved to be adequate to quantify inorganic components and results obtained in chemometric study also demonstrate the feasibility to use this method to discriminate the samples as a function of the conventional ammunition calibers studied. For only one of them, .32 caliber, was the PCA unable to separate samples collected after one shot-relevant in the forensic context, especially in cases of suspected suicide, for example, from the blank samples. The elemental profile obtained in GSR analysis depends on some factors, such as the firearm and ammunition used, occupational contamination of the shooter and the sample collection and extraction method. In this way, chemometric tools are very useful to distinguish small differences observed in the elementary profile, which can result in important information for criminal investigation. In future studies the discrimination of ammunition from the same manufacturer in different calibers and also ammunition from different manufacturers in the same firearm will be evaluated.

\section{Supplementary Information}

Supplementary data are available free of charge at http://jbcs.sbq.org.br as PDF file.

\section{Acknowledgments}

The authors acknowledge the financial support and fellowships from Coordenação de Aperfeiçoamento de Nível Superior (CAPES) (Project Pró-Forenses 3353/2014 Process 23038.007082/2014-03), Conselho Nacional de Desenvolvimento Científico e Tecnológico (CNPq) (311502/2016-4), FAPEMIG (RED-00042-16) and the Civil Police of Minas Gerais. This study was financed in part by the CAPES - Finance Code 001.

\section{References}

1. Romolo, F. S.; Margot, P.; Forensic Sci. Int. 2001, 119, 195.

2. Stevens, B.; Bell, S.; Adams, K.; Forensic Chem. 2016, $2,55$.

3. Meng, H.; Caddy, B.; J. Forensic Sci. 1997, 42, 553.

4. Wallace, J. S.; Chemical Analysis of Firearms, Ammunition, and Gunshot Residue; CRC Press: Boca Raton, 2008.

5. Brozek-Mucha, Z.; Forensic Sci. Int. 2009, 183, 33.

6. Moran, J. W.; Bell, S.; Anal. Chem. 2014, 86, 6071.

7. Reis, E. L. T.; Sarkis, J. E. S.; Neto, O. N.; Rodrigues, C.; Kakazu, M. H.; Viebig, S.; J. Forensic Sci. 2003, 48, 1.

8. Dalby, O.; Butler, D.; Birkett, J. W.; J. Forensic Sci. 2010, 55, 924. 
9. Maitre, M.; Kirkbride, K. P.; Horder, M.; Roux, C.; Beavis, A.; Forensic Sci. Int. 2017, 270, 1.

10. American Society for Testing and Materials (ASTM), E1588-17: Standard Practice for Gunshot Residue Analysis by Scanning Electron Microscopy/Energy Dispersive X-Ray Spectrometry, West Conshohocken, PA, 2017.

11. Brozek-Mucha, Z.; BioMed Res. Int. 2014, ID 428038.

12. Romolo, F. S.; Christopher, M. E.; Donghi, M.; Ripani, L.; Jeynes, C.; Webb, R. P.; Ward, N. I.; Kirkby, K. J.; Bailey, M. J.; Forensic Sci. Int. 2013, 231, 219.

13. Aksoy, Ç.; Bora, T.; Senocak, N.; Aydın, F.; Forensic Sci. Int. 2015, 250, 87.

14. Zeichner, A.; Ehrlich, S.; Shoshani, E.; Halicz, L.; Forensic Sci. Int. 2006, 158, 52.

15. Santos, A.; Ramos, P.; Fernandes, L.; Magalhães, T.; Almeida, A.; Sousa, A.; Forensic Sci. Int. 2015, 247, 62.

16. Tarifa, A.; Almirall, J. R.; Sci. Justice 2015, 55, 168.

17. Yañez, J.; Farías, M. P.; Zúñiga, V.; Soto, C.; Contreras, D.; Pereira, E.; Mansilla, H. D.; Saavedra, R.; Castillo, R.; Sáez, P.; Microchem. J. 2012, 101, 43.

18. Resende, L. V.; Nascentes, C. C.; Talanta 2016, 147, 485.

19. Álvarez-Vázquez, M. A.; Bendicho, C.; Prego, R.; Microchem. J. 2014, 112, 172.

20. Klockenkämper, R.; Knoth, J.; Prange, A.; Schwenke, H.; Anal. Chem. 1992, 64, 1115A.
21. Bruker S2 Picofox ${ }^{\mathrm{TM}}$, TXRF Spectrometer for Element Analysis, User Manual, Order No. DOC-M81-EXX001 V2; Bruker Nano GmbH, Berlin, Germany, 2011.

22. Wobrauschek, P.; J. Anal. At. Spectrom. 1998, 13, 333.

23. Ferreira, M. M. C.; Antunes, A. M.; Melgo, M. S.; Volpe, P. L. O.; Quim. Nova 1999, 22, 724.

24. Souza, A. M.; Poppi, R. J.; Quim. Nova 2012, 35, 223.

25. Ferreira, M. M. C.; Quimiometria-Conceitos, Métodos e Aplicações; Editora da Unicamp: São Paulo, 2015.

26. PICOFOX software, Spectra 7, version 7.5.3.; Bruker Nano GmbH, Berlin, Germany, 2009.

27. MATLAB and Statistics Toolbox Release, R2011a version; The MathWorks, Inc., Natick, Massachusetts, United States, 2011.

28. PLS Toolbox, ${ }^{\circledR}$ 6.7.1 version; Eigenvectors Research: Manson,WA, USA, 2012.

29. Ribeiro, R. O. R.; Mársico, E. T.; Jesus, E. F. O.; Carneiro, C. S.; Conte Jr., C. A.; Almeida, E.; Nascimento Filho, V. F.; J. Food Sci. 2014, 79, T738.

30. Matricardi, V. R.; Kilty, J. W.; J. Forensic Sci. 1977, 22, 725.

31. Taudte, R.V.; Roux, C.; Beavis, A.; Forensic Sci. Int. 2017, 270, 55.

32. Ditrich, H.; Forensic Sci. Int. 2012, 220, 85.

Submitted: February 22, 2019

Published online: July 25, 2019 